the lips of the wound to become quite consolidated, and during this time it requires but little-a cough, a sneeze, a motion of the head, the necessary efforts in the use of a urinal or bed-pan, no matter how careful the nursing - to rupture the newly-formed union; and, as a matter of fact, this often does take place. The aqueous humour then flows away through the wound with a sudden gush, and, where the simple extraction has been employed, carries with it the iris. Doubtless, in this event, it is that portion of the aqueous humour which is situated behind the iris, in the posterior chamber, which is chiefly concerned in the iris prolapse; the aqueous humour in the anterior chamber probably flows off without influencing the position of the iris. The advocates of the simple operation endeavour to prevent secondary iris prolapse by a spastic contraction of the pupil, produced by eserine, which is instilled at the conclusion of the operation, and, again, by some operators, a few hours afterwards. In most instances the desired end is by this means effected. But there is a considerable percentage of the cases in which the contraction of the sphincter iridis is overcome by the pressure of the aqueous humour from behind, and iris prolapse takes place.

How, then, does the formation of a coloboma prevent prolapse of the iris when the wound bursts, as I have described? Not because the portion of iris which is liable to prolapse has been taken away. That would mean nothing less than the whole of that part of the iris which corresponds to the length of the opening in the corneal margin. But the coloboma averts secondary iris prolapse, because it provides a gateway for the aqueous humour contained in the posterior chamber to escape directly through the wound, without carrying with it the iris in its rush; and it is evident that the narrowest coloboma which can be formed will be amply sufficient for the purpose. To my mind, a narrow iridectomy here is no " $\mathrm{mu}$ tilation of the iris," but rather a measure which rests upon a sound scientific basis, and which is calculated to insure the safety of the eye in an important particular.

As to disfigurement of the eye, there is practically none when the coloboma is so narrow, and is situated in the upper part of the iris. The pupil, too, is movable, almost, if not quite as much so, $I$ venture to say, as in most cases of simple extraction, for it is entirely a mistake to suppose that a narrow coloboma renders the pupil immovable. Where there are no adhesions between the pupillary margin and the capsule, as frequently happens, the reaction to light is active, a drop of atropine will dilate the pupil widely, and a drop of eserine will contract it.

That the average acuteness of vision in cases operated on by the simple method is higher than in those operated on with a small iridectomy is a statement of which, I think, there is no proof. The average acuteness of vision in Professor Knapp's last series is, no doubt, very high, and I have seen it quoted as convincing evidence of the advantage in this respect of the simple method. But the high acuteness of vision in that series was not due merely, if indeed at all, to the round pupil, but rather, as Professor Knapp himself states, "the cause of this gain was the subsequent discission of the capsule, which was done in 74 cases." In Professor C. Stedman Bull's recent series, discission was performed in 50 out of the 100 cases, and his average vision is very good. Doubtless in my cases a higher average vision would have been obtained, had I discised the capsule in nearly every case, instead of in only 21 of them. But we must take the public as we find them; and in private practice in this country, when patients obtain sight which enables them to read and write fluently, or even sometimes to sketch and play billiards, as well as to go about with comfort, they are satisfied, and do not care to submit to a further operation, no matter how trifling, in order to increase their power of vision fractionally-no, not even to enable their surgeons to improve the statistics of their operations. In hospital practice our patients are always eager to get to their homes as soon as they find themselves allowed to leave their ward for the day room, and to take a walk in the garden, and it is not easy to submit more than a few of them to secondary capsulotomy.

With regard to the statement, now so often made, that the power of orientation is better in persons operated on by the simple method than where an iridectomy has been done, $\dot{I}$ would say that this may be the case if wide iridectomies are in the minds of those who make this statement, but my patients labour under no difficulty of orientation once they become accustomed to their spectacles.

In conclusion, I may say a few words with reference to the state of the general health required in order that the operation for cataract may be successfully performed. In my opinion, there is hardly any chronic disease which contraindicates this operation, and as ether and chloroform have become unnecessary-as the operation with cocaine is almost painless, as it entails but a short confinement to bed, and as it is the only means of restoring sight in these cases-it should be done whenever the state of the eye renders its prospects good, and the patient's life is likely to last for even a few months longer. Nor do very advanced years form a contraindication. I have trequently operated on persons orer 80 years of age, and in them always with a good result. I know no more pitiable sight than that of an aged and infirm person, with bright mental faculties, who is doomed to pass the last years or months of life depriced of the joy of seeing those who are nearest and dearest; nor is there anything of which I feel more certain than this, that a successful cataract operation gives a renewed lease of life by reason of the improved psychical condition which follows upon it. I do not wish to convey that the state of the patient's general health is a matter of absolute indifference to me, but merely that I do not decline to operate on account of serious organic disease of a chronic nature which, so far as can be known, may not have a fatal termination for months, or, perhaps, for years to come. I have operated successfully in a case of pronounced Bright's disease, as also in the presence of diabetes; nor does chronic disease of the heart, liver, or lungs, even when they are all present in the same individual, cause me to decline to operate.

\section{COLOUR BLINDNESS.}

a Criticisur of the Board of Trade Tests.

BY T. H. BICKERTON,

Oculist Liverpool Royal Infirmary.

THE question asked by Dr. Farquharson in the House of Commons on this matter, and his notification that he would take an early opportunity to bring forward for discussion the subject in its entirety, has attracted a very considerable amount of public attention. How a subject with such important intereste, interests intimately connected with life and property, can have been so thoroughly neglected, and for so long a time, is a question which affords abundant food for reflection. When the facts of the case have been fully and clearly stated, as they will be stated by Dr. Farquharson, it will be surprising if an intelligent public do not command that attention so urgently needed, and compel the department, which has the proud privilege of providing for the safety of the sea travelling community of the first maritime country in the world, to do what should have been done many years ago, its duty.

Until the year 1852 , there were no definite rules regarding the carrying of lights at night by vessels at sea, but in that 5 ear the following regulations became law. Between sunset and sunrise a bright white light is to appear on the foremast head (steamer), a green light on the starboard side, and a red light on the port side. The lights are to be guarded by acreens at least 3 feet long, to prevent them from being seen across the bow, and the expectation, as stated in the official notice, is that the effect of the arrangement proposed will be such, "that in any situation in which two vessels may approach each other in the dark, the coloured lights will instantly indicate to both the relative course of each, that is, each will know whether the other is approaching directly, or crossing the bows either to starboard or to port. This intimation is all that is required to enable vessels to pass each other in the darkest night with almost equal safety as in broad day, and for the want of which so many lamentable accidents have occurred."

At this time the subject of colour blindness had not awakened the attention of practical observers, and it is possible that had the fact that between 3 and 4 per cent. of the whole male population are colour blind then been known, some mode other than by showing red and green lights might have bet $n$ devised to indicate the positions of vessels at sca at night.

But three years later, in the year $185 \overline{5}$, Dr. George Wilson, of Edinburgh, a distinguished member of the medical profession, published an excellent and thorough work, entitled Researches on Colour Blindness. In the pref ace to this work occurs the sentence: "The most practical relation of colour blindness is that which it has to railway and ship signals," and to a consideration of this relationship he devoted many pages. He showed with the greatest clearness how the safety of a vessel lay in the hands of 
men, "look-outs," officers, and pilots, who might be colour blind but unconscious of their defect, or afraid to confess it, and he came to the definite conclusion, that as the colour blind are in a minority in the community, therefore those destined to deal with signals should be selected solely from the majority whose vision was normal. I cannot do better than quote his almost last paragraph : "The professions for which colour blindness most seriously disqualifies are those of the sailor and railway servant, who have daily to peril human life and property on the indication which a coloured flag or a lamp seem to give. Fortunately a ship is seldom under the guidance of a single person, and in Her Majesty's vessels the colour signal men are selected from a large number, and are ascertained to have a quick eye for colour. In merchant ships the choice must necessarily be made from a much smaller number, and the appalling yearly list of lost vessels which appears in our wreck returns awakens the suspicion that more than one of these fatal disasters may have resulted from the mistaken colour of a lighthouse beacon or harbour lamp, which, on a strange coast and with perhaps the accompaniments of a snowstorm or a thick fog, has been wrongly deciphered by a colourblind pilot."

The position of affairs, therefore, was this. The authorities, believing that the want of coloured lights at night at sea had led to "so many lamentable accidents," insisted on coloured lights being carried by all vessels at sea at night, in order to prevent collisions. Dr. Wilson pointing out that since there existed individuals afflicted with a physical defect known as colour blindness, a condition in which, while the vision for form is perfect, and while the colours blue and yellow can be recognised, no certain distinction can be made between the colours red, green, and brown, therefore to such men the exhibition of coloured lights (red and green) by vessels at night could convey no correct significance, and in consequence be no safeguard against collision. He also demonstrated how these colour-blind men were not only unable to detect danger when present, but how they actually created danger otherwise not present; and he urged that unless all colour-blind men were excluded from the position of officer (captain, first, second, and third mate), pilot, and "look-out," the system was fraught with unsuspected danger to all who trusted in it.

Was not his situation a thoroughly logical one. If the "want of coloured lights" had led, as officially stated, to " so many lamentable accidents," then similar lamentable accidents would continue to occur if men, who were physically incapable of interpreting correctly the significance of coloured lights, were placed in positions of trust.

This line of argument the authorities would not at that time acknowledge, and whatever the reason, ignorance, apathy, or rank carelessness, it is a fact that during the controversy which then commenced and has continued until the present day, all recommendations and suggestions by those whose education and line of thought entitled to an opinion, were set at naught, and not until twenty-two years later did the Board of Trade show any sign of life on this important question, and then not of their own free will, but because they were forced by public opinion, did they take any action.

In the December of 1876 a terrible railway collision took place at Arlsey Junction. A letter was written to the Times suggesting colour blindness on the part of the engine driver as the possible cause of the disaster, and this, which was the first letter on colour blindness published in the Times, was followed by many others, and the Whitehall authorities awoke from their long sleep of indifference. At the same time Mr. Jabez Hogg was championing the cause, and the outcome of his energy, and of the public reference to the real dangers of colour blindness, was that the Board of Trade at last grasped the fact that there was such a defect as colour blindness, and admitted "that the serious consequences which might arise from an officer of any vessel being unable to distinguish the colour of the lights and flags which were carried by vessels necessitated all candidates for examination for masters' or mates' certificates passing a test examination as to their ability to distinguish the following colours, which enter largely into the combinations of signals by day or night used at sea-namely, black, white, red, green, yellow, and blue." Having arrived at this conclusion, which, as I have shown, Dr. Wilson came to twenty-two years previously, and, as I shall show, individual shipping firms had, for their own safety, also previously come to, and, what is more acted on, the Board of Trade set themselves to frame tests and regulations with the ostensible purpose of guarding against those "serious consequences" spoken of. How these tests and regulations have fulfilled their object it will be my aim to show, and criticism naturally falls under two heads (a) as to the efficiency of the methods of testing employed to detect colour blindness, and $(b)$ as to the efficiency of the regulations dealing with the colour-blind men when so detected.

The Board of Trade tests are as follows:- "The examiners are supplied with boxes of cards and glasses of several colours-red, green, white, blue, yellow-which have been chosen with great care. The cards should be mixed up. The examiners should then hold up each card separately, and ask the candidate to name the colour; and if the candidate does so without hesitation he is to be regarded as having passed the daylight test" (Circular of March, 1885). The report goes on to say:-"This method is found sufficient to prevent anyone who is more or less colour blind from escaping detection by the examiner, and is sufficient, therefore, for the purpose for which this test is applied."

I deny the truth of this statement, aud I challenge the Board of Trade to name a single man, who has any reputation for knowledge of this subject to lose, who will corroborate it. The test, as a test of the colour sense, is not worth the paper it is written on. And their second test, which takes place in a darkened room, and consists in the candidate being asked to name the colour of various illuminated coloured glass slides, shown separately, is, so far as reliability is concerned, on a par with their first. "If," says the report, "a man can clearly distinguish red from green, and both from black and white, he will be able to follow the international rules for the prevention of collisions at sea." Quite so; but to distinguish colours correctly and to name colours correctly are two very different matters. When will the Board of Trade understand that to ask a candidate to give the name of a colour is a test not of the colour sense but of education in the names of colours, and that to rely implicitly on the correct naming of colours opens the road for an utterly wrong conclusion?

An educated colour blind may, and often does, succeed in guessing the names correctly. According to the Board of Trade, this colourblind man is not colour blind, and, receiving their certificate, he becomes more dangerous to the community than ever, for his defective colour sense is thus authoritatively made perfect colour sense. On the other hand, an uneducated man with a perfect appreciation of colours, though ignorant of their names, would be, according to their rules, colour blind. That at one time the official mind had a glimmering of this fact is indicated by the third test mentioned in the report of 1885 , namely, "that in some cases in which the examiners decide that the applicant has failed, and in which the applicant holds a contrary opinion, as well as in cases whieh may, in the examiners' mind, raise a doubt as to the propriety of passing him, the facts are reported to the Department with full particulars, and the applicant is retested by means of a modification of Holmgren's system of coloured worsteds."

Now, if, as the report says, the first and second tests are "sufficient for the purpose intended," why need a third test? And if, when a doubt in the examiners' mind does arise, he is advised, in order to settle that doubt, to apply a third test, is it not clear to an unbiassed mind that the third test is a more reliable one? Why, then, is it that this last test is not made the crucial test in all cases? This third test (Holmgren's), which depends upon the principle of comparison, and not upon the naming of colours, is safe, simple, and, in my experience, reliable. It is as easily and effectually applied to the uneducated as to the educated, to the foreigner as to the Englishman; and this latter fact is of importance, for a considerable number of our sailors are foreigners.

It is quite impossible to convey to another by words the impression made on our brain by a colour. I may say that a piece of sealing-wax is red, so may others, but it does not follow that the impression formed on my brain and on theirs is identical. A colour-blind man, on being asked the colour of the same piece of sealing-wax, would almost certainly answer "red," that being the usual colour of it, but he could no more describe the sensation produced on his brain that $I$ can tell that on mine. To talk to a colour-blind man about the colour of objects conveys as much information to him as the talking to a deaf person about sound or to a dumb person about speech would do. It is essential, therefore, in order to judge of the impression made by colours on a man's brain, to get him to do something with his hands which will appeal equally to our sense. If we give to a man a skein of coloured wool-green, red, or brown-and he matches, from out of a very large number of skeins of differently coloured wools, green with greens, red with reds, and brown with browns, that man's 
sense of colour is the same as ours, however ignorant he may be of the names of colours. On the other hand, if to match with green he selects red or brown skeins, to match with red, green or brown skeins, and to match with brown, red or green skeins, that man is colour blind, however correctly he may be able to guess at the names of coloured cards or of coloured lights. That the official mind had, as before remarked, a glimmering of this fact the insertion of this third test proved, but I regret to say the ray of intelligence died out, for we find in the report (1887), in the special instructions then issued to the examiners, this test omitted, and I am well aware that, even from the very commencement (1877), it was a dead letter test. So much for the tests; now for the aim of these examinations. It might be supposed-and without any great stretch of the imagination-that while the tests were devised to detect colour blindness, the regulations were framed to exclude the so detected colour-blind men from the sea profession. Such an idea would be, however, a very wide stretch of the imagination, for nothing is further from the intentions of the Board of Trade officials than that. In the first place, colourblind pilots, colour-blind "look-outs," colour-blind A.B.'s, and colour-blind apprentices are, so far as these regulations are concerned, quite competent to assist in the navigation of ships. It is only in case any of these colour-blind men should desire to advance themselves and seek officers' rank that an examination of the colour sense is required.

Let us follow one of these colour-blind men. He applies for a certificate of second mate, and is asked to name the colours of cards and lights - it must be borne in mind that he is generally well aware beforehand what the names of the colours he will be shown are-guesses wrongly, and is rejected as colour blind for three months. At the end of this time he again applies, and either on this or a future occasion guesses correctly, and becomes the proud possessor of a second mate's certificate. Three months ago he was colour blind, now he is not. After sailing as second mate for a greater or less period, he applies for a first mate's certificate. Again he is tested as to his ability to name colours; if he names them correctly, he is not colour blind; if he names them wrongly, he is colour blind; but whether colour blind or not-and this is the point I wish to call special attention to-he obtains his first mate's certificate, though in the former case the remark, "this officer has failed to pass the examination in colours," is written across it. Still later he obtains his master's certificate, and later still, after one or more trials, he names the colours correctly, the endorsement is removed from his certificate, and the public have thrust upon them a full-blown captain upon whose colour sight the lives of hundreds of people, and property to the amount of tens of thousands of pounds, will depend. Yet this officer, though a colour-blind man, is a legalised colour-perfect captain. It may, and probably will, be said that this is an exaggeration. Do not, therefore, accept a single statement on my authority, but read the Board of Trade reports for yourselves. You will find by the report of 1885 , out of 85 colour-blind men, as recognised by the Board of Trade tests, 31 eventually obtained unendorsed certificates; by the report of 1887 , out of 127 colour blinds, at least 14 eventually received unendorsed certificates; and by the report of 1888 , of 66 colour blinds, at least 4 received certificates with a clean bill of health; a total of 45 . Now as colour blindness is congenital and incurable, there are at least 45 officers who were either not colour blind when rejected, or who are colour-blind to-day. Which of the two conditions is the more likely one may be gathered from the fact that, of these 45 legalised non-colour-blind officers, according to the Board of Trade's own showing, 4 at one time or other were unable to distinguish red from green, 22 more called red green, 5 others called green red, and the remainder made mistakes of a marked character. Yet in the face of this disgraceful condition of affairs, a writer in the Nautical Gazette, a journal well known for its advocacy of Board of Trade views, in criticising an article on colour blindness appearing in the JouRnaL, has the assurance to say that " while the members of the profession have been theorising and reading papers about it, practical steps have been taken to check its evil influence in the mercantile marine, and such steps have been attended with satisfactory results. The doctors would introduce intolerable details of a finikin character, while the practical people have really made the examinations eminently practical and quite sufficient for the purposes intended."

I am content to leave my readers and the public to decide whether or not their tests do not stand condemned on their own showing. I would like to know what is the "evil influence" which has been checked? which the "satisfactory results" spoken of ? and, more particularly, who are "the practical people" who "have really made the examinations eminently practical and quite sufficient for the purposes intended?" I say unhesitatingly, and I have the proofs to show, that the tests are practically worthless, that the regulations are a disgrace to those who framed them, that the "evil influence," namely, the number of colour-blind sailors afloat is great, and that the colour-blind reports are a snare and delusion, leading the shipowner and the public into a false belief of security. The shipower and public believed that the Board of Trade examinations secured them against being at the mercy of colour-blind men, but, as I have shown, they do nothing of the kind; and I again repeat that the action of the Board of Trade in knowingly granting to a recognised colour-blind first mate and captain a certificate of competency in seamanship anc navigation, even though it is endorsed "colour blind," is little short of a public scandal. As one writer pertinently asks, "Whoever heard of a shipowner asking to see a certificate? It is very rightly regarded by him in much the same light as a magistrate does a cab-driver's licence, which, until forfeited by misconduct, enables its possessor to follow his calling."

Again, as showing the false impression created by these reports, I may quote the following from the report of 1887 :- "A circular letter was dispatched by the Board in October, 1885, to the authorities governing the various training ships for intended seamen and officers in the mercantile marine, requesting to be furnished with the results of the colour tests as applied on board their respective vessels. Among the more interesting replies were those from the Conway, the Akbar, and Mars. "On board the Conway (Liverpool), of 154 intending officers examined two were found weak in the colour sense, 'and a third, a cadet, of two years' standing, so deficient that he was promptly removed from the vessel. On the Akbar (Liverpool) 148 boys, intending seamen, were examined; four were reported very weak and five others weak in the colour sense." Is not theinference-that all these bnys would be withdrawn from the sea life the one intended by the Board, and also that the testing for colour blindness was due to their action? As a matter of fact the testing had been done months before the circular arrived, and two, not one, of the Convay boys were withdrawn, but only after a strongly-expressed medical opinion; and so far as the Board was concerned, the lads might have remained at sea until this day. Of the four boys on the Akbar, whose colour sight is described as "very weak" but who were typical colour blinds, the public will be scarcely reassured to know that three went to sea. Again, as showing the make-believe-but-do-nothing policy adopted, Captain Milner Moger, of the training ship Clio (Menai Straits), informs me that some time ago the Board of Trade wrote asking for information about the colour vision of the boys on board. He answered that the boys had not been tested, but if the necessary tests were sent down he would be glad to apply them. In reply the Board wrote to the effect that it was no business of theirs to supply the tests, and there the matter ended. It will, however, interest the public to learn that of 258 boys on this vessel, 9 were complete colour blinds; and again, of 158 boys on board the reformatory training ship Clarence (Mersey), 7 were coinplete colour blinds, a total of $\mathbf{1 6}$ on the two ships, all of whom have already or will be drafted into the mercantile marine service to contribute their share in making history for the Wreck Reports. Who, then, are the "practical people" who " have really made the examinations eminently practical and quite sufficient for the purposes intended ?" Where were they in the twenty-two years that elapsed between the pointing out of the dangers of colour blindness by Dr. Wilson and the establishment of any official test whatever? And as to examinations being "quite sufficient for the purposes intended," if by that is meant gulling the public and the shipowner into a feeling of security, I agree with them. But even for this purpose they are sufficient no longer. Speaking from my knowledge of the Liverpool shipowners, I am able to say, that many of them-I think I may almost say most of them-place no reliance on the Board of Trade colour tests, but employ other means to determine the colour vision of their officers and men. This fact is in itself a striking commentary on the official "eminently practical teste,"

But a still more striking commentary on these "eminently practical tests, which are quite sufficient for the purposes intended," is to be found in a letter written by Captain John Smith, of 7, Winslow Street, Walton, Liverpool, to the Shipping and Mercantile Gazette and Lloyd's List, dated August 13th, 1889, which 
reads thus: " On June 19th you were good enough to insert in your valuable paper a letter written by me on colour blindness, and I am pleased to find that my letter and your article commenting on same has attracted considerable interest-notably by the Board of Trade. My object in again troubling you is to impress upon the Board of Trade the necessity for a more perfect means of testing sight. I have lost my position as chief officer in the employ of one of the best and most influential firms in this jort, in whose service I had been for a period of six and a half years, and with a near prospect of command, through not being able to conform to owners' rule and produce a colour-test certificate from their examiner, who, on the contrary, styled me colour blind. I, however, doubted the accuracy of the report, and presented myself to an oculist, but found, alas! the company's examiner's report too true. Now, I call this a very painful case after being thrice passed by the Board of Trade for second, first, and master's certificates. If the Board of Trade examination on any of these occasions had been true I would have directed $\mathrm{my}$ energies towards another way other than the sea to obtain my livelihood. I may say that the defect in my vision has been, in the oculist's opinion, there from birth. I am now, morally and conscientiously, incapable of performing the duties of an officer on board ship at sea, though my certificate bears no endorsement of any kind by the Board of Trade. Many owners I know do not require their officers to pass the colour test, being satisfied with the Board of Trade certificate. But I should think my case ought to be a warning to ship owner not to place reliance on the present Board of Trade test. My colour blindness has destroyed my means of livelihood, and I fearlessly say that the Government test of sight is to blame for this. I am informed that I cannot claim compensation from the Board of Trade because they have not interfered with my certificate; but suppose I follow my arocation and get into collision through my defect, what then? and who would be to blame? I am a young man of 33 , and I have a wife and family depending upon me, and my position at present is very distressing. The best part of my life (Captain Smith has been at sea for twenty years) has been passed in useless toil. My energies and prospec's for the future have been unrewarded and blighted through no fault of my own but through the lax and imperfect way in which I was examined and passed in sight by the test that was adopted by the Board of 'Trade throughout the whole of my examinations.'

What answer the Board of Trade can make to Captain Smith's indictment I know not. They have ruined his life, and they cannot plead ignorance in the doing of it. For years past the worthlessness of their colour tests has been ably pointed out by men of high standing in the profession-Brudenell Carter, Brailey, Nettleship, Jabez Hogg, and last, but not least, Joy Jeffries, of Boston, U.S.A., of whose energies in this direction it is impossible to speak too highly. But all suggestions and recommendations have fallen upon stony ground, and it has remained for one whose best interests the Board of Trade has ostensibly had at heart to stir them up to a sense of the duty they owe, not only to the public, but to every individual sailor who presents himself for their certificate.

It goes without saying that the Board have not interested themselves in obtaining for the victim of their worthless tests any land position which would keep the wolf from the door, though it is true they took the trouble to find out whether such a person as Captain John Smith did really exist. Possibly, when his case is brought, as it will shortly be brought, before the notice of the House of Commons, some appointment may be found for him, and, in any case, the publicity given to his sad experience will have a beneficial result.

It must not be thought that this is an isolated case. It is now no uncommon thing in Liverpool to hear of officers being dismissed for colour blindness who have held, in some cases for years, lucrative and responsible appointments on board ship. Everyone will admit the justice of these dismissals, for upon the correct colour vision of the officer on watch depends the safety of the ship, and, in many cases, the lives of hundreds of helpless passengers and property to the extent of hundreds of thousands of pounds, but everyone will, at the same time, admit the hardship-nay, more, the injustice-done these men by the use of bad Government tests and regulations. The least the Board of Trade sh suld do would be to find some employment for these unfortunate men whose lives and homes they have been the means of wrecking, and a healthy expression of public opinion would do much to compel a public department, not by any means distinguished for its broad and enlightened views, to adopt a sen- sible and humane view of this question; but to expect them to make of their own free will and accord a move in the right direction would be folly, for it must not be forgotten that in instituting tests in 1877, the Board of Trade simply followed the lead of the shipowners, and the credit of recognising the dangers of colour blindness and defective sight belong, the medical profession being excepted, to the latter. It is only right that credit in this matter should be given to those to whom it belongs, and, in this instance, it is the Liverpool Cunard Line who deserve it. The following correspondence, which speaks for itself, is an accurate copy of the letters sent in the year 1876 by the managers of that company to their respective officials:-

"Instructions regarding the ordinary and colour vision of ' look-out'men.-Cunard Line, British and Foreign Steam Packet Company, 8, Water Street, Liverpool, March 22nd, 1876. To Captain - Dear Sir,-Annexed is a letter addressed to the surgeon of your ship. You will at once perceive the importance of being assured of the capability of your 'look-outs,' especially at night; and, besides taking the opinion of the surgeon upon the question, you will kindly impress upon your officers that grave responsibility rests with them in their selection of men for a duty which is of paramount importance.-Yours truly, D. and C. MACIVER."

"To Surgeon - Dear Sir,-As it is of the greatest importance that a thoroughly efficient look-out should be always kept, we have to request that upon the day of muster you will kindly pay particular attention to the eyesight of the men who are told off as look-outs, so as to ascertain whether these men have sufficiently good vision to enable them to see with natural acuteness both by daylight and in the evening, and also readily to distinguish the colours of the different lights displayed by ships at night, so that they may report quickly and accurately and may otherwise fulfil the duties of a thoroughly efficient look out. In the event of your having any doubt as to the possession of the necessary qualifications by any of the men, will you please to report your opinion to the captain, so that these men may not be employed upon a duty for which, in the exercise of your professional discretion, you consider them unfit?-Yours truly, D. and C. MACIVER."

No wonder the Cunard Company were able to say that they had never lost a passenger's life, when men who could grasp a situation so thoroughly as to write such letters were at the head of affairs; and these letters redound to the credit of the medical profession, for it was at the direct instigation of Dr. Caldwell -then surgeon to the crack passenger steamer Russia, but now practising in New York - that they were written. This gentleman also saw (1876) Mr. Thomas Gray, the Permanent Secretary to the Board of Trade, on the subject, and to his representations and to the public agitation over the Arlsey collision (1876) were, I believe, due those tests and regulations (1877) which have been already discussed. But to this day the Board have not recognised the importance of applying the colour test to "look-outs," A.B.'s, and apprentices.

Messrs. D. and C. MacIver considered colour blindness and defective far-sight in a "look out" as fatal to the efficient discharge of his duties. The Board of Trade think differently. So far as their regulations go, a colour-blind man is quite capable of taking his watch as "look-out," and he may have in addition any degree of blindness due to disease or short sight, and yet be quite capable of taking part in the navigation of a ship. That ships have been lost through the defective far sight of "look-outs" and officers no one who reads the evidence given in Board of Trade inquiries can doubt. I have seen professionally officers and men whose sight has been so bad that I would not have trusted them to pilot me across a street, yet the Board of Trade trusted them with the lives of passengers and with valuable ships and cargoes. Perfect farsight is quite as essential as perfect colour sight, and not only should all entering the mercantile marine be subjected to a test as to their visual acuteness for form, but this test should be enforced from time to time. The importance of this latter contention is well shown in a letter received from a gentleman who now occupies a high position in the Board of Trade employ, and which reads thus:

"No man of any experience can doubt for a moment that colour blindness or defective eyesight may bring ships into great danger, and I have not the sligbtest doubt that many accidents have occurred through this cause; the difficulty is to prove it. However, the following happened to me, and although I do not want you to mention my name, you may make what use you like 
of the incident. I was commanding a steamer in the China trade, and have always had excellent eyesight. In the bay on the outward voyage I was knocked by the sea against the rail, and my left cheek-bone broken, and the eye much injured. I could not seo for weeks. By the time 1 arrived at Shanghai the swelling had gone down, and I was nearly well. I went to the best oculist there, and he said my eye was all right. On the voyage home I was taking the altitude of a star about 3.30 A.M., with the second mate. I always take the altitude of the sun with one eye, my right eye; but at night, with the horizon indistinct, it is much better to use both eyes. We took the altitude together, and I found I was $72^{\prime}$ different to his altitude. I at first thought he had taken a different star, and again pointed out the particular star, but on reading off the instruments we were again about $70^{\prime}$ different. By this time it was 4 A.M. ; so I sent word to the first mate to tell him to bring up his sextant, and we all three took an altitude, when to my astonishment I found I was about $70^{\prime}$ different to my two officers. It only then occurred to me that this was caused by my left eye. I took the altitude again with my right eye only, and found I was correct. Now, supposing the altitude had been taken by me without the officer's assistance, and that it had been the first opportunity of getting our position for some days, the ship might have been run ashore on one of the numerous reefs there are in the China Sea, and I should have wondered ever after how it came about. I left the sea after that year."

Until the advent of that letter I had simply considered defective far sight in a sailor as preventing him from detecting danger when present, but now we see that it may directly lead him into danger, and danger of a nature from which it would be impossible to escape. In the first form of danger it is always possible that the other vessel may, by good luck and good management, get out of the way, but sunken reefs, sand banks, and shallows are stationary, and a course being set for them can have but one ending. The case related not only proves the necessity for a periodical testing of the acuteness of vision for form, not necessarily for colour, but it opens up a grave source of danger, a source hitherto unsuspected; and it throws a new light upon the innumerable strandings, wrong courses, etc., with which all who read the Wreck Commissioners' Report are only too familiar.

If those who should be most concerned in ascertaining the real causes of shipping disasters will look at the matter in this light, a distinct advance will have been made. One might have thought that as in most shipping inquiries the evidence as to the colour of the lights, and as to the distance at which they were seen, is bewildering in its contrariness, the first step towards a solution of the difficulty would be to examine on the spot the far sight and colour sight of the witnesses. But the wiseacres whu adjudicate at these inquiries think differently. Though they are aware of the prevalence of colour blindness and of the fact that sailors are no more exempt from short sightedness and eye disease than the rest of the male population, they take it for granted that the witnesses coming before them have perfect far sight and perfect colour sight. One of the remarks most used in order to confound medical experts has been the one, "Point out cases where colour blindness or defective sight has led to disaster." A perfectly fair reply to this would be, "If the eyesight of sailors on colliding vessels were tested in court, examples would multiply." Where one witness swears the colour of a light to have been red, while another is equally positive it was green, there is, in the absence of proof, at least as much reason in believing the correct solution of the discrepancy to be colour blindness on the part of one or other, as to conclude it is found by believing one witness to be lying or drunk. But this form of argument is not necessary, for there are now a sufficient number of cases well authenticated where disaster due to colour blindness or defective sight actually occurred or was narrowly averted.

The first is to be found in the annual report of the Supervising Inspector-General of Steamboats to the Secretary of the Treasury, dated Washington, 1880, and reads as follows:- "On the night of July 5th, 1875, there was a collision near Norfolk, Virginia, between the steam tug Lumberman and the steamship Isaac Bell, the former vessel bound to, and the latter from, Norfolk. The accident occurred at about 9 P.M. on an ordinary clear night, under circumstances which, until recently, seemed more or less myssterious. The master of the steamer and all his officers made oath that at the time signals were made to the tug, the latter was from one to two points on the steamer's starboard bow, and consequently the steamer's graen light only was visible to the approach- ing vessel. Yet the master of the tug, whose statement was unsupported by any other testimony, asserted that the steamer's red light was exhibited, and signalled accordingly. The discrepancy in the statements was so great that many persons uncharitably charged the master of the tug with being intoxicated, although no evidence was ever offered in support of the charge. By this accident ten persons lost their lives. Upon a visual examination of this officer under the rales during the past summer, and during which time there had been no question as to his sight, by the surgeon of the Marine Hospital at Norfolk, he was found to be colour blind, two examinations having been accorded him, with an interval of ten days between them."

A second case is mentioned in the Shipping and Mercantile Gazette and Lloyd's List, dated June 29th, 1881: "The pilot of the City of Austral, which was lost in the harbour of Fernandia, Florida, last April, is proved to be colour blind. In this way it would appear he mistook the buoys, and his mistake cost the owners 200,000 dollars $(£ 20,000)$. An examination showed that at a distance of more than six feet he could not distinguish one colour from another. The physicians attribute the defect to an excessive use of tobacco. The services of the marine surgeons were tendered to the local authorities without fee two years ago, but were declined."

A third case is recounted in a letter from Messrs. Macintyre and Co., Liverpool shipowners: "Our ship Carbet Castle collided in the South Channel, bound from Dundee to Cardiff, in 1879, with the $T$. $H$. Ramien, due, as far as we can now make out, to the colour blindness or short sightedness of the chief officer."

The following account is written by Captain Coburn, who was for many years in the employ of Messrs. Leach, Harrison, and Forwood, of Liverpool, and is to be found in the Mercantile Marine Reporter, vol. xiv, No. 162: "The steamer Neera was on a voyage from Liverpool to Alexandria one night. Shortly after passing Gibraltar, at about 10.30 P.M., I went on the bridge, which was then in charge of the third officer, a man of about 45 years of age, and who up to that time I had supposed to be a trustworthy officer, and competent in every way. I walked up and down the bridge until about 11 P.M., when the third officer and I almost simultaneously saw a light about two points on the starboard bow. I at once saw it was a green light, and knew that no action was called for. To my surprise, the third officer called out to the man at the wheel, 'port,' which he was about to do, when I countermanded the order, and told him to steady his helm, which he did, and we passed the other steamer safely about half a mile apart. I at once asked the third officer why he had ported his helm to a green light on the starboard bow, but he insisted it was a red light which he had first seen. I tried him repeatedly after this, and although he sometimes gave a correst description of the colour of the light, he was as often incorrect, and it was evidently all guesswork. On my return, I applied to have him removed from the ship, as he was, in my opinion, quite unfit to have charge of the deck at night, and this application was granted. After this occurrence I always, when taking a strange officer to sea, remained on the bridge with him at night until I had tested his ability to distinguish colours. I cannot imagine anything more dangerous or more likely to lead to fatal accidents than a colour-blind man on a steamer's bridge."

A similar experience is thus related by Captain Heasley, of Liverpool: "After passing through the Straits of Gibraltar, the second officer, who had charge of the deck, gave the order to 'port,' much to my astonishment, for the lights to be seen about a point on the starboard bow were a masthead and green light but he maintained that it was a masthead and red, and not until both ships were nearly abreast would he acknowledge his mistake. I may add that during the rest of the voyage I never saw him making the same mistake. As a practical seaman, I consider a great many accidents at sea arise from colour blindness."

Fortunately the day is coming when a new régime will be obtained. Dr. Farquharson, by his question in the House of Commons, calling attention to the subject, has done a great public service. It is undoubted that the Board of Trade are beginning to stir in the matter, and we may fully expect that this time the medical views will receive careful attention, and the Board of Trade may feel equally sure that those views will not be narrow or prejudiced. By working together, I have no doubt rules and regulations may be made which, while not bearing harshly upon the sailor, will ensure to the sea traveller immunity from those risks which the present employment of colour-blind and defective far-sighted sailors renders possible. 